\title{
Economic Dispatch with Discontinuous Fuel Cost Function by A Hybrid Method
}

\author{
Sen-Nien Yu, Member IEEE and Yuan-Kang Wu, Member IEEE
}

\begin{abstract}
Economic dispatch with discontinuous cost functions is one of the main functions of power generation operation and control. Two major non-smooth fuel cost functions of units are; units with piecewise quadratic fuel cost functions and fuel cost functions with operating prohibited zones. An electrical power system must be operated most economically while stays within its security limits. This paper develops a hybrid evolutionary programming, Tabu search and direct compensation algorithm to solve the discontinuous economic dispatch (DED) problem. Effectiveness of the new algorithm is demonstrated on three example systems and compared to that of genetic algorithms, evolutionary programming (EP) and hybrid EP, Tabu search and quadratic programming. Numerical results illustrate that the proposed method can provide accurate solutions with reasonable performance.
\end{abstract}

Index Terms - Discontinuous cost functions, evolutionary programming, Tabu search.

\section{REFERENCES}

[1] A. J. Wood, and B. F. Wollenberg, Power Generation Operation and Control, John Wiley and Sons, New York, 1984, pp. 110-121.

[2] D. W. Ross, and S. Kim, "A zoom feature for a dynamic programming solution to economic dispatch including transmission losses,” IEEE Trans. Power Systems, vol. 7, pp. 540-550, May 1992.

[3] K. P. Wong, and C. C. Fung, "Simulated annealing based economic dispatch algorithm,” Proc. Inst. Elect. Eng. C, vol. 140, pp. 509-515, Nov. 1993.

[4] D. C. Walters, and G. B. Sheble, "Genetic algorithm solution of economic dispatch with valve point loading," IEEE Trans. Power Systems, vol. 8, pp. 1325-1331, Aug. 1993.

[5] S. O. Orero, and M. R. Irving, "Economic dispatch of generators with prohibited operating zones: a genetic algorithm approach,” IEE Proc.Gener. Transm. Distrib, vol. 143, pp. 529-533, Nov. 1996.

[6] K. P. Wong, and Y. Y. Wong, " genetic and genetic / annealing Simulated approach to economic dispatch,” IEE Proc.-Gener. Transm. Distrib, vol. 141, pp. 274-278, July. 1994.

[7] H. T. Yang, P. C. Yang, and C. L. Huang, "Evolution programming based economic dispatch for units with nonsmooth fuel cost functions," IEEE Trans. Power Systems, vol. 11, pp. 112-118, Feb. 1996.

[8] S. Khamsawang, C. Boonseng, and S. Pothiya, "Solving the economic dispatch problem with Tabu search algorithm," IEEE ICIT'02, Bangkok, Thailand, pp. 274-278, May 2002.

[9] W. M. Lin, F. S. Cheng, and M. T. Tsay, "Nonconvex economic dispatch by integrated artificial intelligence," IEEE Trans. Power Systems, vol. 17, pp. 307-311, May. 2001

[10] P. Attaviriyanupap, H. K. E. Tanaka and J. Hasegawa, "A hybrid EP and SQP for dynamic economic dispatch with nonsmooth fuel cost function,” IEEE Trans. Power Systems, vol. 17, pp. 411-416, May 2002.
[11] W. M. Lin, F. S. Cheng and M. T. Tsay, "An improved Tabu search for economic dispatch with multiple minima,” IEEE Trans. Power Systems, vol. 17, pp. 108-112, Feb. 2002.

\section{BIOGRAPHIES}

Sun-Nien Yu was born on April 1966 in Miaoli, Taiwan. He received his B. S. and M. S. degrees in Electric Engineering from National Taiwan Institute of Technology in 1991 and 1993 respectively, and Ph. D. from Department of Electrical Engineering, National Taiwan University of Science and Technology in 2004. His research interests are in the operation, planning and analysis of power systems. Since 1996, he has been with Chung Chou Institute of Technology. 